\title{
Building Visual Literacy Skills on Campus:
}

\section{A Toolkit for Multidisciplinary Teaching from University Art Collections}

Mackenzie Brooks, Washington and Lee University USA

Alston Cobourn, East Carolina University USA

Andrea Lepage, Washington and Lee University USA

Elizabeth Teaff, Washington and Lee University USA

\begin{abstract}
Many colleges possess rich art collections that have the potential to expand curricula and address visual literacy in dynamic ways. However, faculty outside studio and art history departments often shy away from integrating art into their teaching. To build visual literacy skills using the campus art collection, a multidisciplinary team created a series of lesson plans for an open web-based toolkit using ACRL's Visual Literacy Competency Standards for Higher Education. This article shares recommendations for others seeking to develop similar multidisciplinary collections-based teaching programs.
\end{abstract}

\section{N TRODUCTION}

Art collections in colleges and universities across the United States are often dispersed throughout the campus, hanging on the walls of offices, displayed in public buildings, or hidden away in storage (Figure I). Collections staff work diligently to engage faculty with the collections, often encouraging them to incorporate artworks into their courses. However, non-art faculty may be unsure of how to make it relevant to their own teaching disciplines. At Washington and Lee University, students have

\footnotetext{
Mackenzie Brooks is associate professor, digital humanities librarian, University Library, Washington and Lee University, Lexington, Virginia; brooksm@wlu.edu. Alston Cobourn is university archivist, Academic Library Services, East Carolina University, Greenville, North Carolina; cobournar8@ecu.edu. Andrea Lepage is professor, Department of Art History, Washington and Lee University, Lexington, Virginia; lepagea@wlu.edu. Elizabeth Teaff is associate professor, head of access services, University Library, Washington and Lee University, Lexington, Virginia; teaffe@wlu.edu.
} 


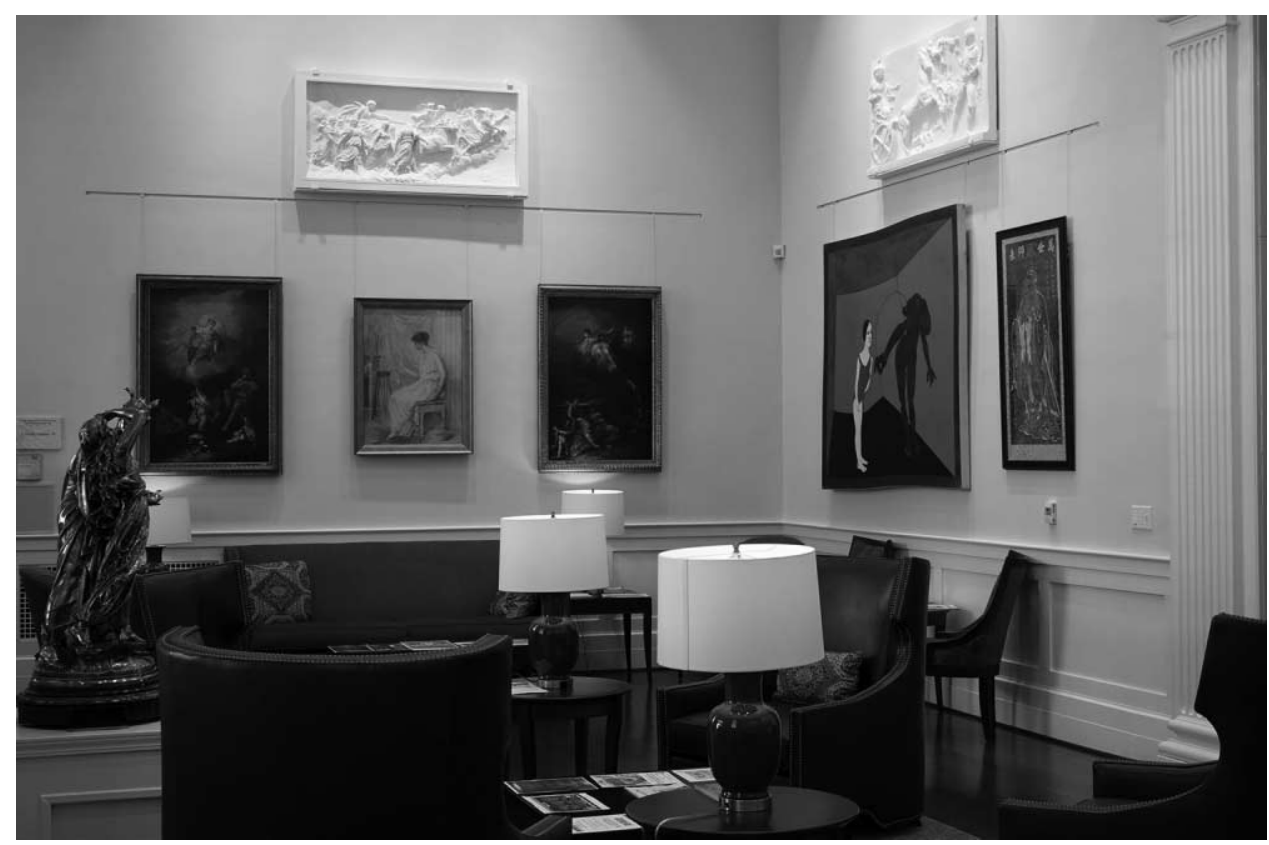

Figure 1. University-owned artwork on display in recently renovated classroom building. Photograph copyright of authors. Please see the online edition of Art Documentation for a color version of this image.

easy access to artworks produced by some of the most important artists of the twentieth century: Salvador Dalí (I904-I989), Robert Indiana (I928-20I8), Frank Stella (b. I936), Andy Warhol (I928-1987), William Christenberry (I936-2016), and Sol LeWitt (I928-2007). Students also have daily access to lesser-known artists, such as Louise Herreshoff (1876-1967), Ben Shahn (1898-1969), Alvin C. Hollingsworth (I928-2000), and Albert Contreras (I933-20I7), whose work has the potential to enhance understanding of numerous historical periods, emphasize lesser-studied geographic regions, and add multiple voices to discussions of art historical narratives.

This article focuses on the multidisciplinary visual literacy program (Toolkit Program) that was developed by a collective consisting of three librarians, an art historian, and three university gallery and collections staff at Washington and Lee University, a small liberal arts institution in Lexington, Virginia. The program makes use of the university's art collection by creating a series of lesson plans focused on objects contained within it. The program organizers invite faculty, staff, and students with diverse expertise to craft open, web-based lessons called "toolkits" that promote the study of artworks based on each author's disciplinary focus. The program coordinators provide invited authors with a variety of resources housed on a website (https:// teachingwithucah.academic.wlu.edu/) to guide them through the process. ${ }^{\mathrm{I}}$ This

I. Invited authors receive a small stipend in acknowledgment of their contribution. The \$250 honoraria were initially drawn from grant money awarded by the Associated Colleges of the South (ACS) to initiate the toolkit program. Future stipends will be supported using available university funds. This project would not be possible without the contributions of Clover Archer, Ron Fuchs, Patricia Hobbs, and David Pfaff. 
collaborative collection development model harnesses the expertise and enthusiasm of individuals from across campus to develop content directly related to curricular needs. The toolkits engage students and faculty from diverse fields, including museum studies, the library, studio art, art history, history, neuroscience, economics, physics, theater, chemistry, English, and digital humanities.

The Toolkit Program utilizes campus artworks to help students and faculty hone their visual literacy skills and to learn about the institution's cultural heritage. The objects in Washington and Lee University's art collection represent gifts from alumni, parents, faculty members, or friends of the university. Together, the artworks reveal a complex history of donor interests that overlaps with larger institutional goals and educational initiatives. By approaching the artworks from multidisciplinary vantage points, the program can give students the tools to become critical consumers of visual media.

The Toolkit Program was implemented to achieve three main goals. First, the program develops critical material to support, promote, and make better pedagogical use of the university's art collection. Second, the program encourages faculty from diverse disciplines to employ art object-based pedagogies in their classrooms. Third, the open online toolkit serves as a model for other universities seeking to develop similar multidisciplinary collections-based teaching programs. By creating lesson plans focused on paintings, sculptures, and screenprints, the Toolkit Program explores creative ways to meet the university's visual and information literacy objectives by looking beyond the library's holdings in rare and archival material. This article describes the process of developing the Toolkit Program, provides discussions of three toolkits that demonstrate the program's pedagogical and visual literacy goals, and provides suggestions for the development of similar programs at other institutions.

\section{LITERAT URE REVIEW}

Today more visual information exists than at any other time in human history. At any waking moment the senses are inundated with imagery-laden data that must be critically evaluated. However, as Denise Hattwig, Kaila Bussert, Ann Medaille, and Joanna Burgess have noted, simply living in a highly visual culture does not "in itself prepare [students] to engage critically and effectively with images and media in an academic environment." ${ }^{2}$ To address this discrepancy, academic libraries have added "visual literacy" to the roster of literacies they address in their educational efforts. The Association of College and Research Libraries (ACRL) defines visual literacy in the following terms:

Visual literacy is a set of abilities that enables an individual to effectively find, interpret, evaluate, use, and create images and visual media. Visual literacy skills equip a learner to understand and analyze the contextual, cultural, ethical, aesthetic, intellectual, and technical components involved in the production and use of visual materials. A visually literate individual is both a critical consumer

2. Denise Hattwig et al., "Visual Literacy Standards in Higher Education: New Opportunities for Libraries and Student Learning," Portal: Libraries and the Academy I3, no. I (20I3): 6I, https://doi.org/10.I353/pla.20I3.0008. 
of visual media and a competent contributor to a body of shared knowledge and culture. $^{3}$

The meaning of visual literacy has shifted and evolved over time, but it is not a new concept. In 20II, ACRL released the Visual Literacy Competency Standards for Higher Education, which provide specific visual literacy learning outcomes for student success. ${ }^{4}$ Scholars continue to expand upon visual literacy frameworks. In the article "Toward a Cohesive Theory of Visual Literacy," Maria D. Avgerinou and Rune Pettersson explain the varied and multidisciplinary approaches required to cultivate the abilities and competencies necessary for literacy in visual language communication. The authors arrive at a six-part theory in which they contend that "visual language must be learned" and "visual language is not universal."

The development of the Toolkit Program is driven by the belief that visual literacy skills form the basis of a solid liberal arts education and provide students with the essential tools to critically view, understand, and produce visual content in an academic setting and beyond. The toolkits focus on artworks that hang in hallways, offices, classrooms, and other public spaces-objects that students and staff may pass by each day without giving them much notice. Following Arabella Sharp, Linda Thomson, Helen J. Chatterjee, and Leonie Hannan, the toolkits capitalize on positive impacts of object-based learning and knowledge acquisition. Sharp et al. contend that "through embodied visual and tangible experience, object-based learning provides a distinct sensory experience that extends beyond didactic precedence of the traditional classroom or lecture theatre setting" regardless of discipline. ${ }^{6}$ Helene Illeris explores the benefits of the aesthetic experience on the learning body that moves beyond the traditional classroom space to engage with surrounding visual and material culture. ${ }^{7}$ Because the Washington and Lee University's collection of art is located throughout

3. "ACRL Visual Literacy Competency Standards for Higher Education," Association of College \& Research Libraries (ACRL), a division of the American Library Association, October 27, 20II, http://www.ala.org/acrl/standards/visualliteracy. The ACRL Visual Literacy Competency Standards were approved in 2000, but later replaced with a related framework for information literacy. See "Framework for Information Literacy for Higher Education," Association of College \& Research Libraries (ACRL), a division of the American Library Association, February 9, 20I5, http://www.ala.org/acrl/standards /ilframework.

4. "ACRL Visual Literacy Competency Standards for Higher Education.” For a recent literature review, see also Barbara Blummer, “Some Visual Literacy Initiatives in Academic Institutions: A Literature Review from I999 to the Present," Journal of Visual Literacy 34, no. I (January 20I5): I-33, https://doi.org/I0.I080/23796529.2015.II67472I. More recently, visual literacy instruction has been reinterpreted through the lens of critical librarianship and feminist pedagogy. In "Break the Stereotype! Critical Visual Literacy in Art and Design Librarianship," Stephanie Grimm and Amanda Meeks "consider critical visual literacy in library instruction as a means of engaging art and design students in conversation concerning social justice within the context of their profession, education, and personal creative practices." Stephanie Grimm and Amanda Meeks, "Break the Stereotype! Critical Visual Literacy in Art and Design Librarianship," Art Documentation 36, no. 2 (Fall 20I7): I74, https://doi.org/IO.I086/694238.

5. Maria D. Avgerinou and Rune Pettersson, “Toward a Cohesive Theory of Visual Literacy,” Journal of Visual Literacy 30, no. 2 (October 20II): I-I9, https://doi.org/I0.1080/23796529.20II.II674687.

6. Arabella Sharp, Linda Thomson, Helen J. Chatterjee, and Leonie Hannan, "The Value of Object-Based Learning Within and Between Higher Education Disciplines," in Engaging the Senses: Object-Based Learning in Higher Education (Abingdon: Routledge, 2016), II3.

7. Helene Illeris, "Learning Bodies Engaging with Art: Staging Aesthetic Experiences in Museum Education," International Journal of Education Through Art I2, no. 2 (June I, 20I6): I53-65, https://doi.org/IO.I386/eta.I2.2.I53_I. 
the campus in spaces that permit close and routine engagement with visual culture, it is especially responsive to Illeris's call for a learning body that experiences art "based on experimental bodily performances [and] can generate aesthetic experiences that are both sensuous, reflective and pedagogical." 8

Examples of object-based learning and visual literacy instruction exist in disciplines beyond art and art history. In "Using Visual Materials to Teach Information Literacy Outside the Art Curriculum," Peggy Keeran, Jennifer Bowers, Katherine Crowe, and Kristen Korfitzen describe an upper-level anthropology course that used documentary art photography from the archives to help teach non-art students how to "interpret, describe, discuss, and ethically use images." ${ }^{9}$ Similarly, the Toolkit Program seeks to instill in Washington and Lee University's students the visual literacy skills that Keeran et al. argue are taught routinely in arts programs, but rarely in other disciplinary areas. In addition, the increased popularity of STEAM (science, technology, engineering, art, and math) initiatives has demonstrated wider interest in exploring the potential curricular value of art and can, as Aaron D. Knochel suggests, create the "opportunity for collaboration across disciplines through practices and performances where a kinship can be formed over hands-on experiences of making." ${ }^{\text {Io }}$ The Toolkit Program demonstrates a decidedly multidisciplinary approach, combining contributions from faculty and staff in the humanities, sciences, libraries, and museum departments within a single repository.

\section{OVERVIEW OF THE TOOLKIT PROGRAM}

Washington and Lee University's Toolkit Program is an ongoing initiative for which the organizers recruit toolkit guest authors from a growing number of disciplines to produce instructional content on objects of their choosing. Artworks selected for toolkits match author interests, address gaps in the knowledge of the university art collection, and emphasize the study of artworks produced by members of underrepresented or minoritized groups including women and artists of color. The organizers present guest authors with a selection of artworks and offer some information about the larger art historical context surrounding the piece. Each toolkit features one or more artworks from the university collection, a variety of supporting materials, brief explanatory text to provide a context for the overall presentation, prompts for student discussion or writing assignments, and a recommended reading and viewing list for further engagement and exploration. These cover a variety of disciplines including environmental history, art, engineering, philosophy, creative writing, law, history, and journalism.

Toolkit authors are provided with suggestions and resources but may rely on their preferred set of presentation tools. Presentation modes range from fully formatted

\footnotetext{
8. Illeris, "Learning Bodies Engaging with Art," I58.

9. Peggy Keeran et al., "Using Visual Materials to Teach Information Literacy Outside the Arts Curriculum," Art Documentation 38, no. I (Spring 2019): 157, https://doi.org/10.1086/702894.

I0. Aaron D. Knochel, "An Object-Oriented Curriculum Theory for STEAM: Boundary Shifters, Materiality and per (Form)Ing 3D Thinking," International Journal of Education Through Art I4, no. I (March I, 2018): 37, https://doi.org/io .I386/eta.I4.I.35-I.
} 
PowerPoint files with presenter notes to web pages to interactive $3 \mathrm{D}$ photogrammetry projects. In addition, toolkit content varies according to the disciplinary needs of each invited author but may include downloadable presentations, detailed speaker's notes, primary data, class handouts, audio recordings, video recordings, timelines, and interactive models. Therefore, the toolkits together allow users to explore a range of digital presentation modes, all of which offer users the ability to customize the artviewing experience. Authors have licensed all toolkits under a Creative Commons Attribution-NonCommercial-ShareAlike 4.o International License. Additionally, through a grant from the Associated Colleges of the South, the authors are able to offer a modest stipend to toolkit creators.

While most of the works may be found in public spaces, some of the works referenced in the toolkits have been moved from storage and placed on display. When possible, mini-iPads are mounted nearby to encourage engagement with online materials in front of the artwork, thereby augmenting the viewing experience with multimedia content. Because of the web-based platform, educators from around the world can access the resources in the Toolkit Program and digital surrogates of select pieces of artwork from the university's collection. The organizers held an information workshop to bring the Toolkit Program to the attention of the university community, and each toolkit is disseminated widely via social media. The organizers utilize Google Analytics to track patterns of web traffic, number of users, and number of page views. To date, the site has received over Io,ooo page views, with notable increases each time a new toolkit is released via social media.

Several authors created toolkits about temporary exhibitions installed in the Staniar Gallery, the university's non-collecting temporary exhibition space. These toolkits enabled other instructors outside of the art department to utilize the gallery as a pedagogical resource, and this resulted in greater overall exhibition attendance. This was a welcome outcome since gallery staff had already invested resources to bring artists to campus and to install the exhibitions. The gallery toolkits also benefited the visiting artists, who were able to share them at other institutions that exhibited the same body of work.

Three sections of the website- "For Lesson Creators," "Image Resources," and "Copyright" - were created with the specific goal of enabling others to develop similar programs at their home institutions. "For Lesson Creators" provides a sample template for structuring a toolkit and was developed to help local toolkit creators as well as others who desire to implement a similar program. The "Image Resources" and "Copyright" sections provide instructors with resources and information that would enable them to be responsible users of copyrighted and licensed materials while creating their own toolkits. These sections are essential components of meeting the overall goal to spread visual literacy knowledge and implement best practices. First, these sections sought to make it easier for instructors to model responsible scholarship to their students when creating toolkits. Second, both sections were crafted with the intention of increasing the instructor's understanding of the ethical, legal, and monetary issues surrounding the creation and use of images. The "Image Resources" section contains a list of resources for finding freely available images that can be used in 
the creation of toolkits. The "Copyright" section provides information about copyright law, its purpose, public domain, and exemptions that can apply to teaching, such as

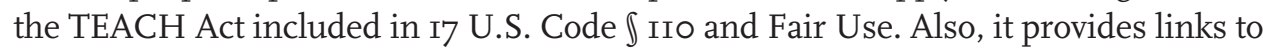
online tools for assessing if an image belongs to the public domain and fair use claims. Finally, it provides links to relevant reputable sources of additional information, such as the College Art Association's 2015 online resource Code of Best Practices in Fair Use for the Visual Arts. ${ }^{\text {II }}$ The following sections describe three toolkits in detail and discuss their connections to ACRL's Visual Literacy Competency Standards.

\section{TOOLKIT: ALBERT CONTRERAS}

In 2005, California-based artist Albert Contreras (I933-20I7) donated a series of twenty-four paintings to the university with the hope that the gift would live on as his legacy (Figure 2). Though Contreras was well known in the Ig6os and I970s in Sweden where he was an active minimalist painter, ${ }^{\mathrm{I}}{ }^{2}$ the university had not researched the donated paintings. When building renovations forced university collections staff to seek a new location for the works, the colorful acrylic gel panels were relocated to the art building, and several were installed in an art history faculty member's office. Research revealed that Contreras made many similar donations of artworks to other campuses around the country. As such, the team's art historian crafted a toolkit based on Contreras's work in the hope that other institutions with similar gifts might make use of and build upon the research and materials to engage their own students with his work. In addition, the works were later united in the first on-campus exhibition of the university's US Latina/o and Latin American artworks.

The Contreras toolkit (https://teachingwithucah.academic.wlu.edu/albert-contreras/) relates to one of the main program goals: to increase knowledge of the institution's history through the study of lesser-known artists. According to ACRL Visual Literacy Standard Three, "The visually literate student interprets and analyzes the meanings of images and visual media." ${ }^{\text {"3 }}$ Contreras's work presented the university with the opportunity to teach students how to engage meaningfully with abstract artworks that they might see each day passing through the halls of the art building. The toolkit presents multiple ways of interpreting and analyzing Contreras's work: based on his place in a larger art historical narrative, through an examination of his technique and unique artistic process, by investigating the particular circumstances of the gift, and by exploring themes of memory and legacy. Aspects of the toolkit also touch on topics of mental health and art therapy-Contreras abandoned painting for twenty-five years and returned to artmaking only after years of mental health treatment. ${ }^{\mathrm{I} 4}$ One art historian at Washington and Lee University incorporated aspects of the Contreras toolkit into his curriculum and found it so effective that he has continued to use the lesson each

II. College Art Association, “Code of Best Practices in Fair Use for the Visual Arts," https://www.collegeart.org/pdf /fair-use/best-practices-fair-use-visual-arts.pdf.

I2. Dave Hickey et al., Albert Contreras (New York: Marquand Books, 2013), I4.

I3. "ACRL Visual Literacy Competency Standards for Higher Education."

I4. Hickey et al., Albert Contreras, I4. 


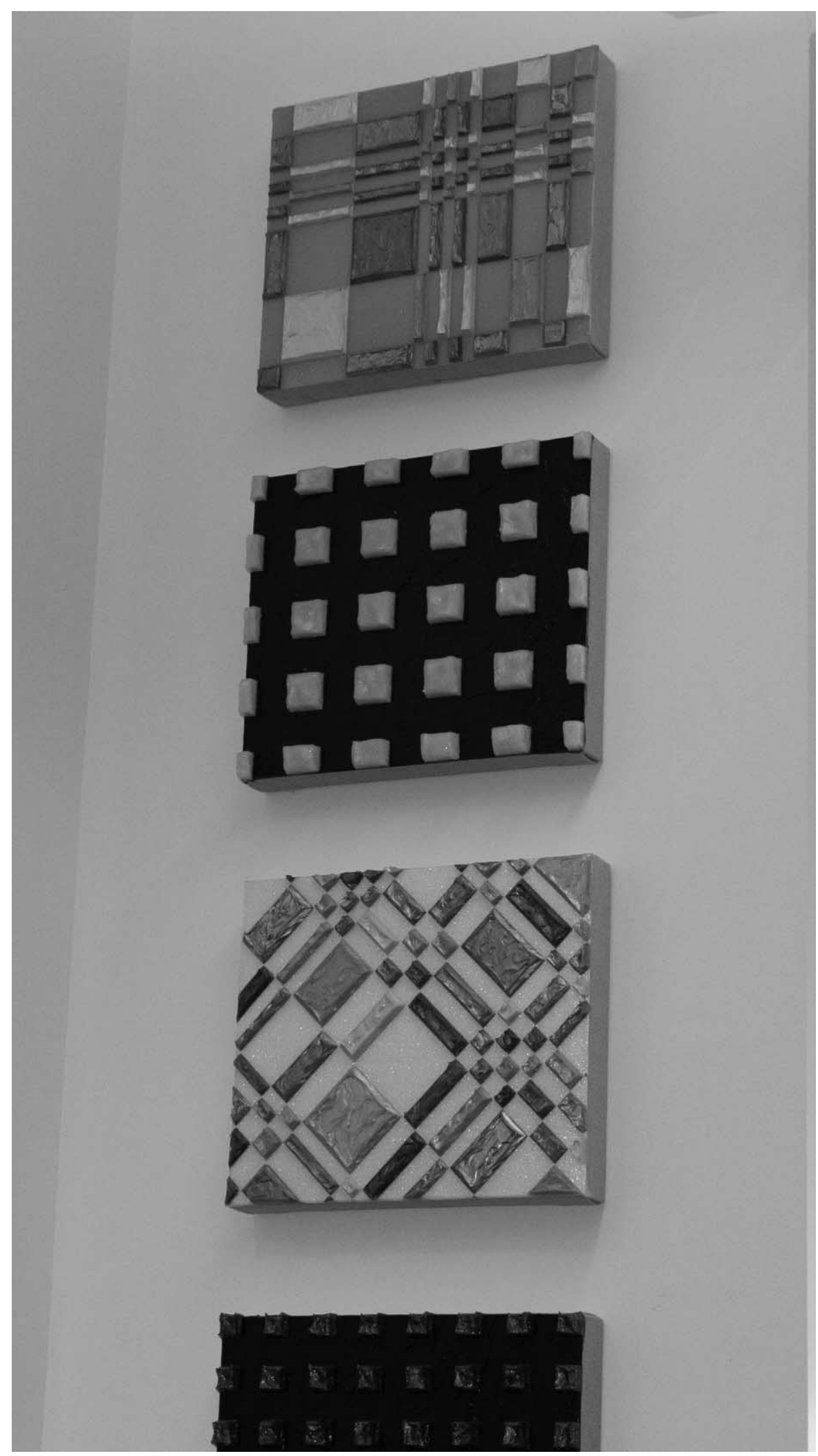

Figure 2. Paintings by Albert Contreras on display in faculty member's office. Photograph copyright of authors. Please see the online edition of Art Documentation for a color version of this image. 
time he teaches the course. A series of paintings once overlooked has now been studied by hundreds of students.

To encourage the interpretation of Contreras's work from multiple viewpoints, the Toolkit Program's art historian created a downloadable slide presentation with images, quotations from the artist, and detailed speaker's notes that facilitate incorporation of the material into a classroom setting. The presentation includes reproductions of Contreras's artwork for which the author sought and secured permission from the artist and the Peter Mendenhall Gallery. The toolkit also includes primary documents in the form of correspondence between Contreras and a former university president, a detailed timeline of the artist's life, a video showing Contreras's process, and prompts for additional discussion. In the process of seeking image permissions, the author was also able to inform the artist, who later passed away in June 2017 at age eighty-four, about the project, and perhaps affirm that his memory would live on at this institution.

\section{TOOLKIT: PHOTOGRAMMETRY OF UNCLE TOM'S CABIN VASES}

In collaboration with the university ceramics curator Ron Fuchs, two librarians wrote a toolkit about a pair of nineteenth-century vases (Figure 3) depicting scenes from Harriet Beecher Stowe's Uncle Tom's Cabin published in I852 (https://teachingwithucah.aca demic.wlu.edu/uncle-toms-cabin/). Their toolkit focused on the novel and its historical impact and was intended for use in an American history or literature class. The vases depict two famous scenes in the novel: Eliza Harris fleeing over the ice with her son Harry and Little Eva hanging flowers around Uncle Tom's neck. The large vases are rendered in a Rococo revival style popular in the mid-nineteenth century. Produced about a decade after the original publication of Uncle Tom's Cabin, the vases were likely used as decorative objects in a wealthy home to signal the abolitionist values of their owners. This toolkit focuses on teaching visual literacy within a social and historical context. In addition, the intricate formal features of these vases proved ripe for experimentation with emerging digital methods. To demonstrate the multidisciplinary potential of the Toolkit Program, the digital humanities librarian created a second toolkit about the Uncle Tom's Cabin vases. With the goal of demystifying photogrammetry for others, the digital humanities librarian focused the second toolkit on the process of creating a three-dimensional model of one of the vases (https://teaching withucah.academic.wlu.edu/photogrammetry-of-uncle-toms-cabin-vase/)

While there are long-established practices for remediating printed text or twodimensional art, it is only recently that technology has advanced sufficiently to enable the creation of accurate digital surrogates for three-dimensional objects. ${ }^{15}$ Photogrammetry is the process of creating measurements or $3 \mathrm{D}$ digital models from a series of photographs. It can be performed on objects, rooms, or even whole buildings. Cultural heritage institutions use the resulting $3 \mathrm{D}$ models to study and provide access to their artifacts. Objects can be viewed in a web browser or inserted into a virtual reality

I5. Tanya M. Johnson, "Let's Get Virtual: An Examination of Best Practices to Provide Public Access to Digital Versions of Three-Dimensional Objects," Information Technology and Libraries 35, no. 2 (June 30, 2016): 39, https://doi.org /ro.6or7/ital.v35i2.9343. 


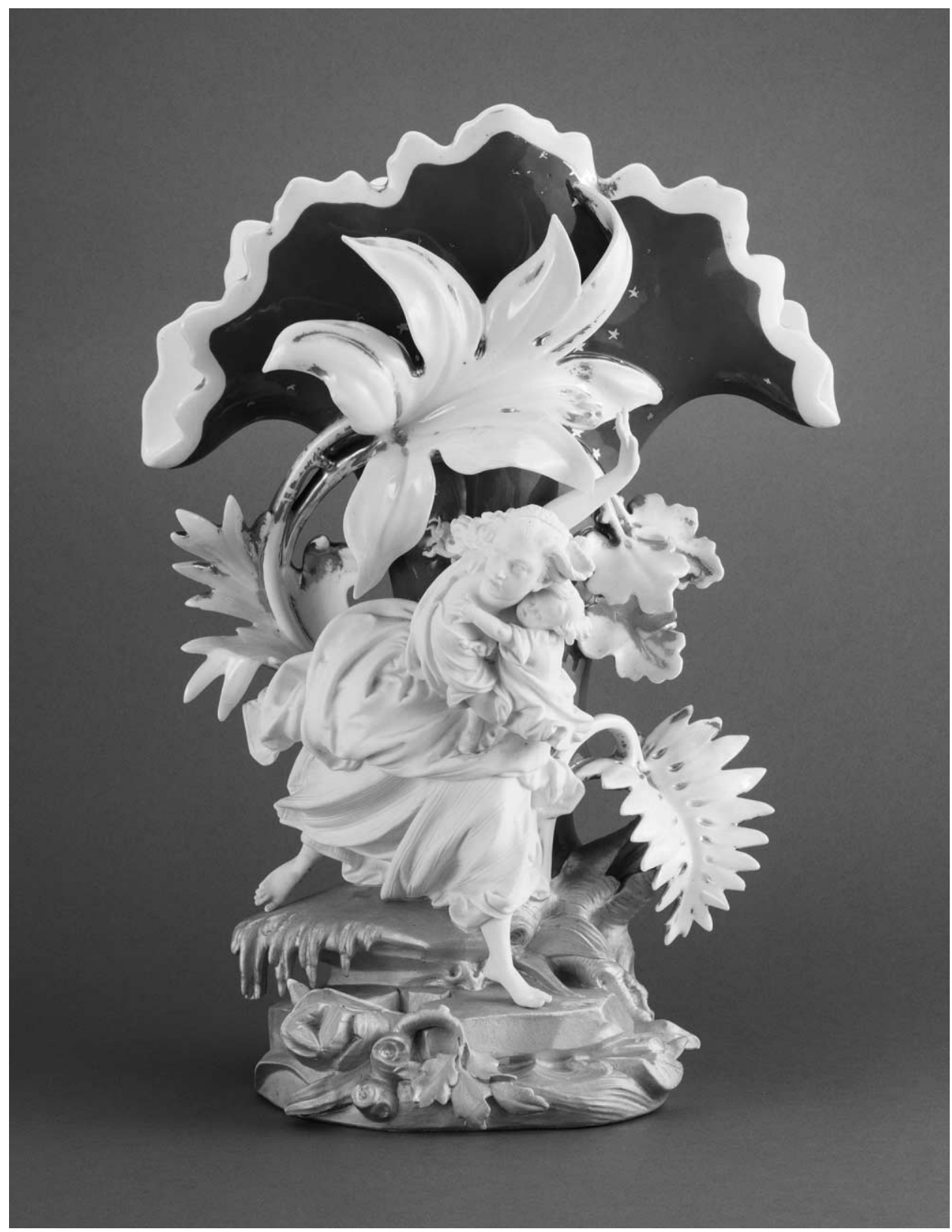

Figure 3. Image of nineteenth-century vase depicting scenes from Stowe's Uncle Tom's Cabin. Photograph courtesy of Museums at Washington and Lee University. Please see the online edition of Art Documentation for a color version of this image.

environment for manipulation. Students can virtually "handle" objects that are normally behind glass or view the objects in the context of a larger environment. While the photogrammetry process is time-consuming, it is not out of reach for students. It can even be accomplished with a mobile phone. As with many digital humanities 
methods, the act of making can lead to deeper understanding and analysis. ${ }^{16}$ ACRL Visual Literacy Standard Six states, "The visually literate student designs and creates meaningful images and visual media." ${ }^{77}$ The focused and sustained attention required to create their own models better enables students to interpret existing models.

This toolkit necessitated the collaboration of several departments at the university. The ceramics curator and a collection assistant transported one vase to the science building for photographing. They were the only staff members with training that permitted them to touch or rotate the vase safely, though after the completion of the photogrammetry process, the vases could be handled virtually by students, faculty, and the broader public. An information technologies (IT) staff member, David Pfaff, was responsible for the photography, which took several hours. The reflective glaze on the vase made it difficult to capture photographically, and some of the decorative elements created unavoidable shadows. The IT staff member retouched the photographs and monitored the software while the model was created. The project resulted in an engaging 3D model, and each participant learned about the other's discipline and methods. The model and the toolkit could be created only with the cooperation of several people, all of whom received credit in the final publication.

In addition to a description of the photogrammetry process and the $3 \mathrm{D}$ model, the author included multiple videos in this toolkit. One video depicts a time-lapsed view of the photography process. Another shows the $3 \mathrm{D}$ model being created in the software with text annotations to enable others to replicate the process (Figure 4). The toolkit concludes with activities for interacting with the $3 \mathrm{D}$ model and suggests alternate pedagogical uses for photogrammetry. This toolkit provides a starting place for instructors from any discipline to incorporate photogrammetry or $3 \mathrm{D}$ objects into their teaching. Photogrammetry creates a new avenue for students to interact with and analyze their surroundings and can be utilized in the context of objects in the art collection or physical spaces around campus. As the use of virtual and augmented reality becomes more widespread in higher education classrooms, ${ }^{18}$ it is increasingly important for students to understand the technology behind what they are viewing.

\section{TOOLKIT: COPYRIGHT AND ROBERT INDIANA}

Two of the librarians were inspired to create a set of toolkits about pieces by Robert Indiana (I928-20I8) in the university collection that, at that time, hung on permanent display in an underutilized library classroom where students, faculty, and staff infrequently engaged with them (Figure 5). The university's Indiana portfolio is one of twenty-five portfolios of artist's proofs Indiana retained for himself in I97I upon publication of an edition of 200. Focusing on Indiana's use of poetry and themes of social justice, the librarians created toolkits that would engage myriad disciplines,

\footnotetext{
I6. Stephen Ramsay, "On Building," in Defining Digital Humanities: A Reader (London: Ashgate Publishing, 20I3),

I7. "ACRL Visual Literacy Competency Standards for Higher Education."

I8. Bryan Sinclair, "The Promise of Virtual Reality in Higher Education," EDUCAUSE Review, http://er.educause .edu/articles/20I6/3/the-promise-of-virtual-reality-in-higher-education.
} $243-45$. 


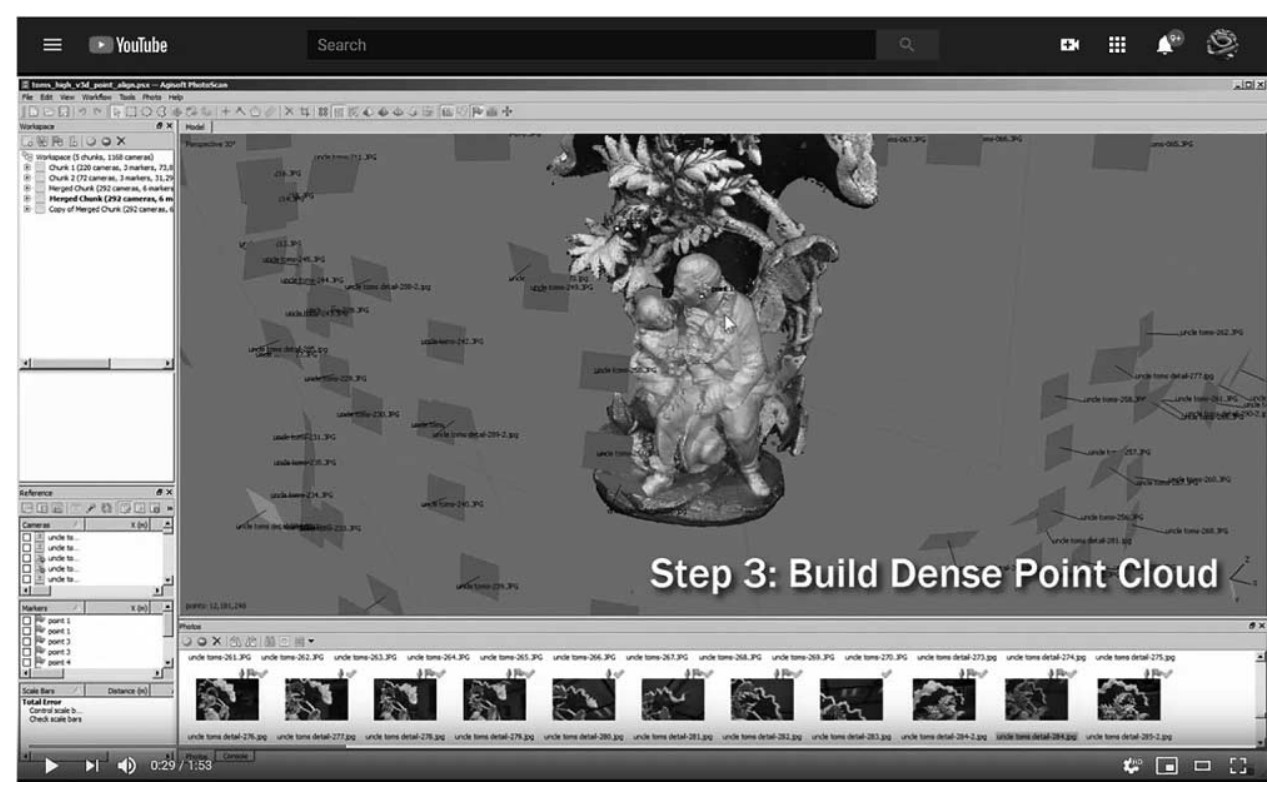

Figure 4. Screenshot of YouTube video created to illustrate photogrammetry process: https://www.youtube $. \mathrm{com} /$ watch?time_continue $=3 \& v=S E Z t G Q E P p Q M \&$ feature $=$ emb_logo. Please see the online edition of Art Documentation for a color version of this image.

from creative writing to politics (https://teachingwithucah.academic.wlu.edu/robert -indiana/). The main goal of these toolkits is to encourage students to conduct close readings of historical texts and images and link the information garnered to today's social concerns.

As expressed in ACRL Visual Literacy Standard Seven, the library profession promotes student understanding of the complex issues surrounding the creation and use of images so that they can be responsible scholars, information consumers, and information creators. Standard Seven states that "the visually literate student understands many of the ethical, legal, social, and economic issues surrounding the creation and use of images and visual media, and accesses and uses visual materials ethically." ${ }^{9}$ Its performance indicators state that students follow "ethical and legal best practices when accessing, using and creating images" and that students cite "images and visual media in papers, presentations, and projects." ${ }^{2 \circ}$ Because the librarians have copyright expertise and one of the Indiana works in the collection, Black and White Love (I968 serigraph of I97I painting), is surrounded by copyright-related legal issues, creating a toolkit focused on copyright law felt like a natural fit.

Indiana's $L O V E$ variations are among his most iconic works. He did not include a copyright symbol on the works themselves, an action that was required under the copyright law of the time in order to maintain full legal authority over subsequent

I9. "ACRL Visual Literacy Competency Standards for Higher Education." 20. "ACRL Visual Literacy Competency Standards for Higher Education." 


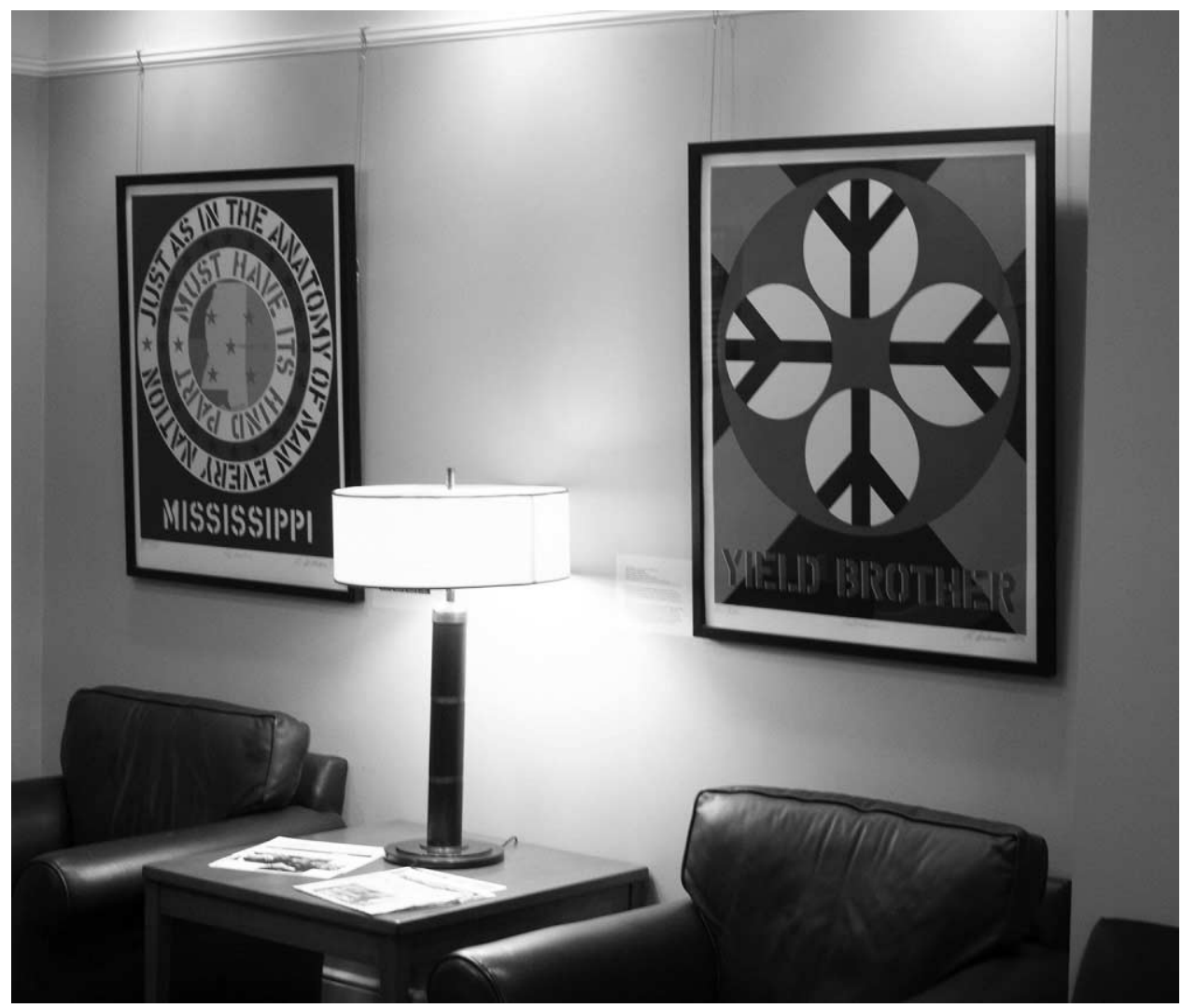

Figure 5. Robert Indiana prints on display in renovated classroom building. Photograph copyright of authors. Please see the online edition of Art Documentation for a color version of this image.

reproductions. ${ }^{2 \mathrm{I}}$ As a result, other artists and companies throughout the world were legally permitted to reproduce these iconic interlocking letter designs on merchandise, such as paperweights, without obtaining Indiana's permission. ${ }^{22}$ The toolkit includes a series of questions that ask students to explore the ethical issues surrounding the reuse of someone else's work and the legal considerations of copyright law. As one potential assignment, students may write an essay on the differences between plagiarism and copyright infringement. In the process of looking, studying, researching, and writing, students also learn about current copyright law and the ways in which they can protect their own rights and avoid infringing upon the rights of others.

In a second toolkit focusing on two of Indiana's works, The Calumet (I97I serigraph of I96I painting) and The Confederacy: Mississippi (I971 serigraph of I965 painting), students are asked to conduct a close reading of Henry Wadsworth Longfellow's epic poem The Song of Hiawatha (I855) referenced in Indiana's The Calumet. Students also read about violence perpetrated by the $\mathrm{Ku}$ Klux Klan to provide them with

2I. L. F. Pinkerton and J. T. Guardalabene, The Art Law Primer (New York: Nick Lyons Books, I988), II.

22. Susan Elizabeth Ryan, Robert Indiana: Figures of Speech (New Haven: Yale University Press, 2000 ), 220. 
background information on Indiana's The Confederacy series in which he references Klan activity in the town of Bogalusa, Louisiana. ${ }^{23}$ Through these readings, students analyze and create meaning from the images as outlined in ACRL Visual Literacy Standard Three. As an information literacy assignment, students create their own images as described in ACRL Visual Literacy Standard Six. ${ }^{24}$ Students are asked to create a piece of artwork based on a contemporary social justice issue of concern and to find primary and secondary sources related to their topic.

\section{CONCLUSION}

One important goal of the Toolkit Program is to facilitate the development of similar programs at other institutions. Another principle benefit of the Toolkit Program is its ability to build and sustain information about the collection over time by the creation and continual curation of the toolkit's web presence. It helps to start with a small set of toolkits by inviting only one or two guest curators at any given time so as not to overwhelm collections staff. A main goal of the Toolkit Program project was to facilitate the use of the art collection by individuals who might not feel comfortable utilizing art in their classrooms. Virtual and face-to-face conversations are thus crucial to build collaborations across the campus and help to achieve one of the Toolkit Program's goals to draw faculty attention to the breadth of the university's art collection.

In some cases, image use fees were cost prohibitive and limited the ability to post high-quality images, even though the project has a strong fair use claim: All of the photographs were used for an educational, non-commercial purpose. Despite the fact that some of Indiana's LOVE works are not protected by copyright, the artist's estate still holds the right to monetarily license the photographic reproduction of his works. The required yearly fees were an unsustainable option both because they were cost prohibitive and would require ongoing maintenance. Instead the authors opted to take their own photographs of the works in situ in order to show how faculty, staff, and students encounter the artwork in everyday non-museum settings. The photographs are "transformative works" rather than substitutes of the original artworks. They include furniture arrangements, architectural elements, and demonstrate how the artwork looks in relation to other pieces. In addition, the purposeful use of lowresolution photographs prevents others from using them for commercial purposes.

One crucial lesson learned is that assessment must be integrated into the program from the start, a step overlooked in the initial development of the Toolkit Program. The program organizers received informal feedback from instructors and students but aspire to solicit feedback from future users more systematically. Faculty are already conducting their own course assessments, and assessing the outcomes of toolkit use may not be a priority for them. As such, assessments of the toolkits should be short and target the specific ACRL learning objectives addressed in each toolkit. Links to a brief assessment tool were added to each toolkit lesson after its development.

23. Douglas O. Linder, “Bending toward Justice: John Doar and the Mississippi Burning Trial,” Mississippi Law Journal 72, no. 2 (2002): 73I-80.

24. "ACRL Visual Literacy Competency Standards for Higher Education.” 
Going forward, assessments will be created alongside the toolkit content and released at the same time.

The program coordinators quickly learned that toolkits produced by a non-art historian are most useful as templates for other non-art historians invited to craft new toolkits. While it initially seemed logical to have the participating art historian craft the first toolkit examples, invited participants expressed concerns that they would not be able to provide enough art historical information about artworks. This feedback encouraged the program organizers to redefine some of the key project goals. Because the program is aimed at areas of study outside of the arts, with the assumption that the art department faculty already utilize the art collection, the authors found it essential to encourage toolkit authors to emphasize their own disciplinary expertise. To assuage the concern some invited authors expressed about not being able to provide sufficient historical background for an artist or artwork, it was helpful to have an art historian or university collections staff member produce a brief written introduction to each artist. Doing so allowed authors to focus attention on crafting toolkits that capitalized on their own disciplinary expertise.

Non-art historians brought unique perspectives to the study of art and made artworks relevant to the daily lives of the students who pass by the artworks each day. The university's energy specialist, Jane Stewart, paired two paintings that feature windmills (James Hamilton, Snow Storm with Figure, c. 1875, and David Brewster, Fish Lake Aermotor, 2007) to discuss modern issues of climate change and the global need for reliable alternatives to fossil fuels (https://teachingwithucah.academic.wlu.edu /james-hamilton-and-david-brewster/). A creative writing instructor, Laura Brodie, employed a series of paintings produced by early twentieth-century American artist Louise Herreshoff Eaton to demonstrate ekphrastic poetry, a descriptive form of writing that "involves a meeting of creative minds - the poet meets the artist halfway, offering a creative response to the artist's work" (https://teachingwithucah.academic.wlu.edu /ekphrastic-poetry/). ${ }^{25}$ The gallery director, Clover Archer, constructed an exercise around Los Angeles-based street artist Mr. Brainwash's Tomato Spray Can (20I4) to teach students about themes of commercial art, consumerism, and appropriation. The exercise encouraged students to select a commercial logo, transform it into an artwork, and discuss the ways that the process of appropriation also transformed the original intent and meaning of the logo (https://teachingwithucah.academic.wlu.edu/mr-brainwash/). These unique multidisciplinary perspectives on the study of art successfully assert the relevance of the arts to other academic units throughout the university.

One of the most important benefits of this program was the personal connections cultivated while working to produce toolkits. For practical purposes, participants found it helpful to collaborate with colleagues to create jointly authored toolkit lessons to relieve some of the concern of taking on a new and unfamiliar task. Perhaps more importantly, collaborative work also stimulated conversation among colleagues and facilitated incorporation of multiple perspectives into many of the toolkits. Students from

25. Laura Brodie, "Ekphrastic Poetry | Teaching with UCAH," Teaching with UCAH, https://teachingwithucah .academic.wlu.edu/ekphrastic-poetry/. 
diverse disciplines worked with professors as well as gallery and collections staff. Librarians and art historians collaborated with curators, information technologists, and poets. Inviting experts from two or more fields promoted alternative understandings and analyses and cultivated broader discussions.

Similar visual literacy work has been happening in museum settings for years, but the toolkits incorporate artwork located outside the traditional museum structure into curricula and encourage faculty outside of art and art history to engage with the creation of instruction of visual literacy principles. In the process, the authors learned a great deal about artworks in the university's collection, many of which were studied for the first time as a result of this program. In addition, the development of toolkits helps to underscore the importance of the arts in liberal arts education, enhances visual literacy beyond the art department, introduces faculty outside the art department to university collections, and fosters collaboration across disciplinary lines, between faculty, students, and staff. While it is difficult for a small collections staff to develop content for an entire collection, much more ground can be covered when faculty and students from across campus contribute energy, enthusiasm, and expertise to collection content development. This program has enabled others to be ambassadors for visual literacy within the campus community and beyond. In addition, the program contributes to achieving the university's mission to promote student curiosity, lifelong learning, and engaged global citizenship. 